ORIGINAL ARTICLE

\title{
Assesment of the TEI index of myocardial performance in dogs with doxorubicin-induced cardiomiopathy
}

\author{
Evaluación del índice de desempeño miocárdico de TEI en perros \\ con cardiomiopatía inducida por doxorrubicina
}

\author{
MG Sousa ${ }^{\mathrm{a}}$, D Paulino-Junior ${ }^{\mathrm{b}}$, JPE Pascon ${ }^{\mathrm{b}}$, GB Pereira-Neto ${ }^{\mathrm{b}}$, R Carareto ${ }^{\mathrm{a}}$, AA Camacho ${ }^{\mathrm{b}}$ \\ ${ }^{a}$ College of Veterinary Medicine and Animal Science, The Federal University of Tocantins, Araguaina, Brazil. \\ ${ }^{\mathrm{b}}$ College of Agricultural and Veterinary Sciences, São Paulo State University, Jaboticabal, São Paulo, Brazil.
}

\begin{abstract}
RESUMEN
El desarrollo de una cardiomiopatía dosis dependiente es la principal limitación para el uso de doxorrubicina en protocolos de quimioterapia tanto en seres humanos como en animales. En estos casos, la función global del miocardio puede ser cedida, teniendo como resultado signos atribuibles a la insuficiencia cardíaca congestiva. En este estudio, nosotros investigamos la capacidad del índice de desempeño miocárdico de Tei para identificar disfunción de miocardio en perros sanos tratados con doxorrubicina a una dosis cumulativa de $210 \mathrm{mg} / \mathrm{m}^{2}$ en un periodo de 147 días, comparándolo con otros indicadores ecográficos estándar de función sistólica y diastólica. Nuestros resultados indicaron que el índice de Tei, el tiempo de relajación isovolumétrica, el período de pre-eyección, y la relación período de pre-eyección/tiempo de eyección ventricular izquierda pudieron identificar los efectos cardiotóxicos de doxorrubicina en la función cardíaca cuando sólo $60 \mathrm{mg} / \mathrm{m}^{2}$ habían sido administrados, mientras los parámetros estándar sistólicos y diastólicos, incluso el diámetro sistólico del ventrículo izquierdo, la fracción de eyección y la fracción de acortamiento, necesitaron por lo menos $120 \mathrm{mg} / \mathrm{mg}^{2}$ para empeorar. Se concluye que la terapia prolongada con antraciclinas perjudica las funciones sistólica y diastólica, que pueden ser documentadas antes adicionándose el índice de Tei a la evaluación ecográfica estándar en animales que reciben doxorrubicina.
\end{abstract}

Palabras clave: cardiotoxicidad, antraciclinas, disfunción cardiaca, quimioterapia.

\section{SUMMARY}

The development of a dose-dependent cardiomyopathy is the main limitation for the use of doxorubicin in chemotherapy protocols in both humans and animals. In this setting, the global myocardial function may be compromised resulting in signs of congestive heart failure. In this study, we investigated the ability of the Tei index of myocardial performance to identify myocardial dysfunction in healthy dogs receiving doxorubicin to a cumulative dose of $210 \mathrm{mg} / \mathrm{m}^{2}$ over 147 days, comparing it with other standard echocardiographic indicators of systolic and diastolic function. Our results indicated that the Tei index, the isovolumic relaxation time, pre-ejection period and the pre-ejection period-to-left ventricular ejection time ratio were able to identify the cardiotoxic effects of doxorubicin on cardiac function when only $60 \mathrm{mg} / \mathrm{m}^{2}$ had been administered, while the standard systolic and diastolic parameters, including left ventricular diameter at systole, ejection fraction, and fractional shortening needed at least $120 \mathrm{mg} / \mathrm{mg}^{2}$ to deteriorate. We concluded that prolonged anthracycline therapy compromises both systolic and diastolic functions, which may be documented earlier by including the Tei index evaluation to the standard echocardiographic assessment of animals receiving doxorubicin.

Key words: cardiotoxicity, anthracycline, cardiac dysfunction, chemotherapy.

\section{INTRODUCTION}

Doxorubicin is an anthracycline drug indicated for the treatment of several neoplasms. Its mechanism of action is not completely understood, but it is likely tobe related with toxic oxidative metabolites, which are not as well metabolized by the heart as they are by other organs (Olson and Mushlin 1990). Although indicated in both medical and veterinary practices, doxorubicin has a limited use owing

Accepted: 18.04.2013.

* BR-153, Km 113, Campus EMVZ, Araguaina, TO, Brazil; marlos@uft.edu.br to the development of a dose-dependent cardiomyopathy that can lead to congestive heart failure (Susaneck 1983, Maudlin et al 1992, Souza and Camacho 2006).

Because doxorubicin cardiotoxicity tends to be related to the cumulative dose and dosing schedule (Ganz et al 1996), several protocols have been proposed to minimize the toxic effects on the heart. In our laboratory, when doxorubicin was given to healthy dogs at $30 \mathrm{mg} / \mathrm{m}^{2}$ each 21 days until a cumulative dose of $240 \mathrm{mg} / \mathrm{m}^{2}$ was achieved, signs of congestive heart failure developed 165 days after chemotherapy started. However, an increase in the left ventricular diameter at systole and diastole, and reductions in both fractional shortening $\left(\mathrm{FS}_{\%_{6}}\right)$ and ejec- 
tion fraction $\left(\mathrm{EF}_{\%}\right)$ were documented much earlier, at 91 days post initiation (Silva and Camacho 2005).

In human beings, it has been demonstrated that diastolic dysfunction also occurs during anthracycline-based chemotherapy (Tjeerdsma et al 1999). Nonetheless, only few veterinary studies have evaluated diastolic parameters in animals treated with doxorubicin. Several methods may be used to investigate diastolic function. Standard echocardiography can be used to assess the isovolumic relaxation time (IVRT), and flow deceleration times through the analysis of atrioventricular flows. Moreover, the Tei index (TEI), an index of myocardial performance useful in estimating ventricle function, demonstrated to correlation with indicators of diastolic function, including the diastolic peak (-dP/ dt) and tau in people with ischemic heart disease (Tei et al 1997). Also, in a porcine model, this index showed a direct correlation with the ventricular stiffness constant, and it was inversely related to the ejection fraction, thereby supporting its clinical use not only as an indicator of diastolic performance, but as a measure of global ventricular function (Lacorte et al 2003). TEI is defined as (Isovolumic contraction time + Isovolumic relaxation time)/Left-ventricular ejection time, as reported elsewhere (Tei 1995, Tei et al 1995).

Therefore, the goal of this study was to assess the Tei index in healthy dogs receiving doxorubicin, and to compare this index with some standard echocardiographic indicators of systolic and diastolic functions.

\section{MATERIAL AND METHODS}

\section{ANIMALS}

Seven mature mongrel dogs of either sex, with mean weight of $17.6 \mathrm{~kg}$, were enrolled in the study. The dogs were housed in individual cages and were given free access to water and provided with commercially available dog food twice a day during the entire period of the experiment. The study was conducted in accordance with the guidelines outlined in the National Institutes of Health Guide for the Care and Use of Laboratory Animals, and was previously approved by the institutional Commission on Ethics and Animal Welfare under protocol 1538/06. Health status of the animals was assessed prior to the beginning of the experiment based on results of both physical and laboratory examinations.

\section{INDUCTION OF DOXORUBICIN CARDIOMYOPATHY}

To induce the cardiomyopathy, 30 milligrams of doxorubicin per $\mathrm{m}^{2}$ of body area were given intravenously at 21day intervals (M30, M60, M90, M120, M150, M180, and M210) until a cumulative dose of $210 \mathrm{mg} / \mathrm{m}^{2}$ was achieved.

\section{ASSESSMENT OF CARDIAC FUNCTION}

A transthoracic echocardiographic examination was performed in every dog using a 5.0 MHz mechanical sec- tor transducer. Echocardiographic images were recorded with a simultaneous lead II electrocardiogram for offline measurements. A single experienced veterinary cardiologist was responsible for all echocardiographic studies.

To obtain better images, hair was clipped between the right $3^{\text {rd }}$ and $6^{\text {th }}$ intercostal spaces, and left $2^{\text {nd }}$ and $7^{\text {th }}$ intercostal spaces. Generous coupling gel was applied to these areas of the thorax immediately before echocardiography was started. Measurements were taken by using two-dimensional-guided M-mode on the standard right parasternal short-axis view at chordae tendineae level for measurement of left ventricular end-systolic $\left(\mathrm{LV}_{\mathrm{s}}\right)$ and end-diastolic $\left(\mathrm{LV}_{\mathrm{d}}\right)$ dimensions, which were used for calculation of $\mathrm{EF}_{\%}$ and $\mathrm{FS}_{\%}$. With dogs positioned in left lateral recumbency, either apical four-chamber view or apical five-chamber view images were acquired. Gain and filter settings were adjusted individually to reduce background noise and result in clear flow signals. To acquire inflow and outflow velocity spectra during the same cardiac cycle, the Doppler sample volume was placed midway between mitral inflow and left ventricular outflow in the apical five-chamber view. Left-ventricular ejection time $\left(\mathrm{LV}_{\mathrm{ET}}\right)$ was determined as the duration of left ventricular outflow profile, and TEI was calculated by using the formula $\left(A-\mathrm{LV}_{\mathrm{ET}}\right) / \mathrm{LV}_{\mathrm{ET}}$ where $A$ is the time interval between the end and the onset of transmitral flow (Tei and others 1995).

The apical five-chamber view was also used to measure the pre-ejection period (PEP) from the electrocardiogram $\mathrm{Q}$ wave to the onset of the left-ventricular outflow. IVRT was measured as the interval between aortic valve closure and the onset of mitral inflow. Also, the PEP-to- $\mathrm{LV}_{\mathrm{ET}}$ ratio $\left(\mathrm{PEP} / \mathrm{LV}_{\mathrm{ET}}\right.$ ) was calculated. Mitral peak velocities of early (E) and late (A) diastole were acquired at the tips of the mitral valve leaflets, and were used to calculate the E-to-A ratio (E/A). Based on aortic flow spectra, stroke index (SI) and cardiac index (CI) were also calculated. These parameters were chosen because they are indicators of either systolic or diastolic function included in the standard echocardiogram and may be measured easily without the need of advanced echo modalities, such as tissue doppler imaging.

All echocardiographic measurements were recorded at baseline and at 21-day intervals until a cumulative dose of $210 \mathrm{mg}$ of doxorubicin per $\mathrm{m}^{2}$ of body area was achieved. M-mode measurements were performed in accordance with the recommendations of the American Society of Echocardiography. At least three consecutive beats were measured and averaged for each parameter. All Doppler parameters were recorded using pulsed-wave Doppler, and special care was taken to perform these measurements with the Doppler beam as parallel as possible to the presumed direction of blood flow. 


\section{STATISTICAL ANALYSES}

The mean and standard deviation of all echocardiographic measurements were calculated. A repeated measures analysis of variance was applied to the various echo measures to investigate differences over time. When the differences were determined by the analysis of variance to be significant, the post hoc Tukey-Kramer multiple comparisons test was used to further investigate differences. The software Prism for Windows v. 5.04 (Graphpad Software, San Diego CA, USA) was used for all statistical analyses, and significance was set at $\mathrm{P}<0.05$.

\section{RESULTS}

No complications were seen during the induction of doxorubicin cardiomyopathy. Although several alterations have been detected over time in the echocardiographic examinations, the dogs enrolled in the study presented no clinical signs at all, but a mild reduction in body weight during the induction period.

Table 1 gives the results of echocardiographic parameters. Significant differences along time are reported. A significant increase in $\mathrm{LV}_{\mathrm{s}}, \mathrm{PEP}, \mathrm{IVRT}, \mathrm{PEP} / \mathrm{LV}_{\mathrm{ET}}$, and TEI was observed along doxorubicin therapy. Also, significant decreases were seen in $\mathrm{EF}_{\%}$ and $\mathrm{FS}_{\%}$. Although not statistically significant, an increase was documented for $\mathrm{LV}_{\mathrm{d}}$, as well as a decrease for E/A, SI and CI in accordance with the infusion of cumulative doses of doxorubicin. On the contrary, $\mathrm{LV}_{\mathrm{ET}}$ remained relatively unchanged during therapy.

The Tei index values at M60 showed differences from the baseline values, meaning that $60 \mathrm{mg}$ of doxorubicin resulted enough to cause changes in myocardial performance as revealed by such parameter. Interestingly, $\mathrm{EF}_{\%}$ attained significant difference from the baseline value only at M120, whereas for $\mathrm{FS}_{\%}$, a significant change was only documented at M150. Regarding diastolic function, significant changes were observed in IVRT at M60. Differently the E/A did not differ significantly from its baseline value at all times, but some animals showed an inverse mitral E/A at M150.

\section{DISCUSSION}

Although it was not the primary aim of this study to describe the myocardial morphologic and functional alterations owing to doxorubicin, it is clear that this drug produces cardiotoxicity in a dose-dependent fashion (Maudlin et al 1992). As far as the cumulative dose of $120 \mathrm{mg}$ of doxorrubicin $/ \mathrm{m}^{2}$ was achieved, most dogs included in this investigation demonstrated significant alterations in the indicators of systolic function. As the infusion of the drug progressed, several parameters changed statistically as compared to baseline values. When the cumulative dose of $210 \mathrm{mg} / \mathrm{m}^{2}$ had been given, an important sys- tolic dysfunction was documented in all dogs based on echocardiographic indicators. This is in agreement with previous studies that demonstrated the progressive cardiotoxicity of doxorubicin, resulting in both clinical and echocardiographic findings similar to those of idiopathic dilated cardiomyopathy (Silva and Camacho 2005, Souza and Camacho 2006). Interestingly, none of the animals of this study developed signs of severe heart failure, such as pulmonary edema, as reported by Maudlin and colleagues (1992), whose investigation showed that heart failure may arise in dogs as soon as $90 \mathrm{mg}$ of doxorubicin/ $\mathrm{m}^{2}$ had been given. This finding may be attributable to variations in individual responses to anthracycline therapy (Souza 2004, Silva and Camacho 2005).

According to the echocardiographic indicators of cardiac function, a marked deterioration in systolic and diastolic functions occurred as the cardiomyopathy progressed. Thus, the greater the cumulative dose of doxorubicin, the highest the degree of myocardial dysfunction documented. It is well known that such cardiotoxicity develops because arachidonic acid metabolites, histamine, platelet-activating factor, and free radicals are released into the cardiac muscle, leading to functional damage and myocardial remodeling (Toyoda et al 1998, Sousa and Camacho 2007). In this regard, our results are similar to those described by Souza (2004) and Silva and Camacho (2005) along the induction of doxorubicin cardiomyopathy. These authors also identified a progressive increase of the left ventricular diameter at systole, with diminished contractility. However, a major problem of using both shortening and ejection fractions to estimate contractility rely on the influence played by preload and afterload on them, therefore making them less specific in quantifying systolic function (Ferraris 2007, Boon 2011). Also, because the ejection fraction in this investigation was calculated using the unidimensional left ventricular measures in systole and diastole processed by Teichholz's corrected cubic equation, the values of $\mathrm{EF}_{\%}$ are proportional to those of $\mathrm{FS}_{\%}$ (Henik 2002). Nonetheless, because PEP-to- $\mathrm{LV}_{\mathrm{ET}}$ ratio is inversely proportional to myocardial contractility (Sousa et al 2007), its increase observed herein is consistent with a reduction in contractility.

Regarding diastolic function, our results demonstrated some degree of impairment after the cumulative dose of $90 \mathrm{mg} / \mathrm{m}^{2}$ was reached. Although in many veterinary studies the diastolic function has historically been left aside, diastolic dysfunction has been documented in human patients treated with doxorubicin for breast cancer (Tjeerdsma et al 1999). Interestingly, Marchandise et al (1989) and Stoddard et al (1992) have demonstrated that diastolic dysfunction might occur prior to systolic dysfunction, making it an earlier indicator of doxorubicin cardiotoxicity. In this study, the diastolic impairment was demonstrated by the prolongation of IVRT, as well as by the reduction of the E/A. Although the majority of pre- 


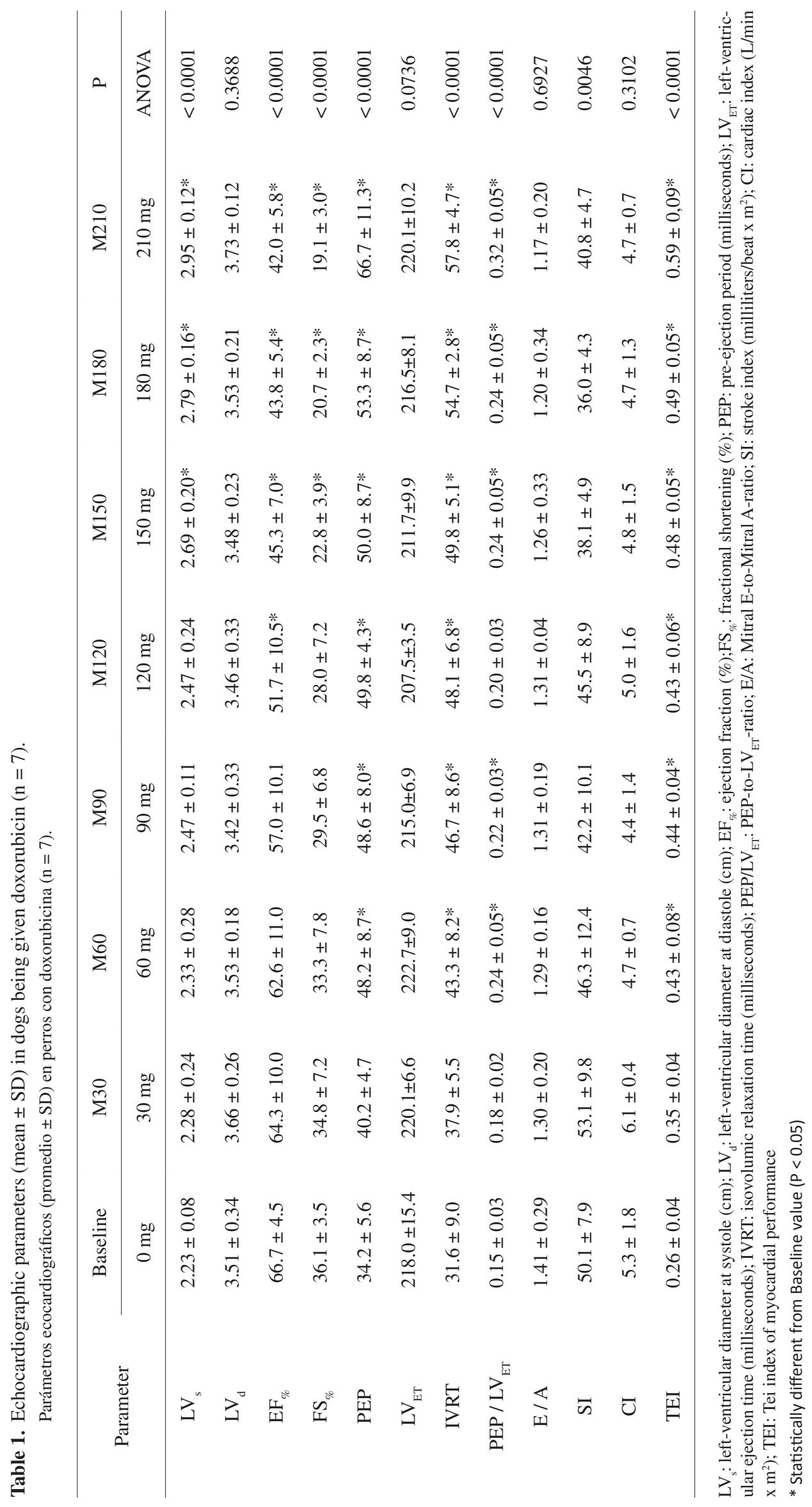


vious studies using this model of cardiomyopathy only focused on systolic function, some clinical signs actually may be attributable to the diastolic impairment, which was well documented in this investigation. The diastolic compromise may result from foci of myocardial fibrosis caused by ultra-structural lesions promoted by the anthracycline therapy (Susaneck 1983, Marchandise et al 1989, Stoddard et al 1992). Although right ventricular diastolic function have not been evaluated in this research, it is likely that the same alterations observed for the left ventricle occurred on its right counterpart, since the cardiotoxicity of doxorubicin affects the whole heart (Toyoda et al 1998, Sousa and Camacho 2007).

According to the Tei index of myocardial performance, a global cardiac dysfunction was documented in the dogs of this investigation. This index is calculated using both isovolumic contraction time and isovolumic relaxation time, as well as the left ventricular ejection time, therefore allowing the assessment of systolic and diastolic function concurrently (Tei 1995, Pellet et al 2004). Besides being very simple to calculate, this index performs independently of ventricular geometry, and is likely less influenced by heart rate, arterial pressure, preload and afterload, being especially useful to evaluate remodeled hearts (Tei et al 1995, Sousa et al 2007). The cardiac dysfunction documented by the Tei index in this study is in agreement with the other echocardiographic indicators of systolic and diastolic function, which also changed along the induction of doxorubicin cardiomyopathy. However, the changes in the Tei index were identified much earlier than the standard indicators of cardiac function, making it especially useful for monitoring the cardiotoxicity of anthracycline therapy.

The main limitations of this study rely on the small number of animals enrolled, as well as the absence of a more detailed echocardiographic evaluation of diastolic function, including tissue doppler imaging and strain to better characterize diastolic dysfunction. In conclusion, this investigation showed that the prolonged therapy with doxorubicin impairs both systolic and diastolic functions, and the Tei index may be used as an easily calculated non-invasive indicator of global cardiac function.

\section{REFERENCES}

Boon JA. 2011. Veterinary echocardiography. $2^{\text {nd }}$ ed. WileyBlackwell, Ames, USA.

Ferraris SR. 2007. Ecocardiografia. En: Belerenian G, Mucha CJ, Camacho AA, Grauet JM (eds). Afecciones cardiovasculares en pequeños animales. $2^{\mathrm{a}}$ ed. Inter-médica, Buenos Aires, Argentina, Pp 129-177.

Ganz WI, KS Sridhar, SS Ganz, R Gonzalez, S Chakko, A Serafini. 1996. Review of tests for monitoring doxorubicininduced cardiomyopathy. Oncology 53, 461-470.

Henik RA. 2002. Ecocardiografia e ultra-som Doppler. En: Tilley LP, Goodwin JK (eds). Manual de cardiologia para cães e gatos. $3^{\mathrm{a}}$ ed. Roca, São Paulo, Brazil, Pp 67-94.
Lacorte JC, SE Cabreriza, DG Rabkin, BF Printz, L Coku, A Weinberg, WM Gersony, HM Spotnitz. 2003. Correlation of the Tei index with invasive measurements of ventricular function in a porcine model. J Am Soc Echocardiogr 16, 442-447.

Marchandise B, E Schroeder, A Bosly, C Doyen, P Weynants, R Kremer, H Pouleur. 1989. Early detection of doxorubicin cardiotoxicity: interest of Doppler echocardiographic analysis of left ventricular filling dynamics. Am Heart $J$ 118, 92-98.

Maudlin G, P Fox, A Patnaik, BR Bond, SC Mooney, RE Matus. 1992. Doxorubicin-induced cardiotoxicosis: clinical features in 32 dogs. $J$ Vet Intern Med 6, 82-88.

Olson RD, PS Mushlin. 1990. Analysis of prevailing hypotheses. Rev Am Soc Exp Biol 4, 3076-3086.

Pellett A, WG Tolar, BS Merwin, EK Kerut. 2004. The Tei index: methodology and disease state values. Echocardiography 21, 669-672.

Silva CEV, AA Camacho. 2005. Alterações ecocardiográficas em cães sob tratamento prolongado com doxorrubicina. Arq Bras Med Vet Zootec 57, 300-306.

Sousa MG, AA Camacho. 2007. Cardiotoxicidad por doxorrubicina en perros. En: Belerenian G, Mucha CJ, Camacho AA, Grauet JM (eds). Afecciones cardiovasculares en pequeños animales. $2^{\mathrm{a}}$ ed. Inter-médica, Buenos Aires, Argentina, Pp 297-301.

Sousa MG, R Carareto, AB De-Nardi, FL Brito, N Nunes, AA Camacho. 2007. Effects of isoflurane on Tei-index of myocardial performance in healthy dogs. Can Vet $J 48$, 277-283.

Souza RCA. 2004. Avaliação neurohumoral e hemodinâmica de cães clinicamente normais submetidos ao tratamento com doxorrubicina. Tesis Doctoral, College of Agricultural and Veterinary Sciences, São Paulo State University, Jaboticabal, Brazil.

Souza RCA, AA Camacho. 2006. Neurohormonal, hemodynamic, and electrocardiographic evaluations of healthy dogs receiving long-term administration of doxorubicin. Am J Vet Res 67, 1319-1325.

Stoddard MF, J Seeger, NE Liddell, TJ Hadley, DM Sullivan, J Kupersmith. 1992. Prolongation of isovolumetric relaxation time as assessed by Doppler echocardiography predicts doxorubicin-induced systolic dysfunction in humans. J Am Coll Cardiol 20, 62-69.

Susaneck SJ. 1983. Doxorrubicin therapy in the dog. J Am Vet Med Assoc 182, 70-72.

Tei C. 1995. New non-invasive index for combined systolic and diastolic ventricular function. J Cardiol 26, 135-136.

Tei C, LH Ling, DO Hodge, KR Bailey, JK Oh, RJ Rodeheffer, AJ Tajik, JB Seward. 1995. New index of combined systolic and diastolic myocardial performance: a simple and reproducible measure of cardiac function - a study in normals and dilated cardiomyopathy. J Cardiol 26, 357-366.

Tei C, RA Nishimura, JB Seward, AJ Tajik. 1997. Noninvasive Doppler-derived myocardial performance index: correlation with simultaneous measurements of cardiac catheterization measurements. J Am Soc Echocardiogr 10, 169-178.

Tjeerdsma G, MT Meinardi, WTA Van Der Graaf, MP van de Berg, N Mulder, H Crijns, EGE de Vries, DJ van Veldhuisen. 1999. Early detection of anthracycline induced cardiotoxicity in asymptomatic patients with normal left 
ventricular systolic function: autonomic versus echocardiographic variables. Heart 81, 419-423.

Toyoda Y, M Okada, MA Kashem. 1998. A canine model of di- lated cardiomyopathy induced by repetitive intracoronary doxorubicin administration. J Thorac Cardiovasc Surg 115, 1367-1373. 